\title{
Soil Nutrient Budgets and Flows in Smallholder Farming System of Ethiopia: Review
}

\author{
Negessa Gadisa \\ Ethiopian Institute of Agricultural Research, Holeta Agricultural Research Center \\ Corresponding author: Negessa Gadisa
}

\begin{abstract}
Primary nutrients like N, P and K are common for crop production in smallholder farms in Ethiopia. Nutrient budgets and flows in most farming systems play a crucial role in agricultural production and may lead to either depletion or accumulation of nutrients. This review showed trends of nutrient flows and balances in a farming systems as a result of different deriving forces, differences in farming systems, variability in soil fertility and management strategies. The review highlights the potential sources of nutrients and balance approaches as an indicator of soil nutrient mining in smallholder farming systems in the country. There is insufficient awareness on the levels of nutrient depletion in Ethiopia due to limited research conducted related nutrient mining and depletion even though there are different assessments made by different authors at small holder levels.
\end{abstract}

Keywords: Soil nutrient budget, Soil fertility, nutrient replenishment, crop production

DOI: $10.7176 / \mathrm{JBAH} / 11-14-02$

Publication date:July $31^{\text {st }} 2021$

\section{INTRODUCTION}

Soil nutrient loss is caused by many factors such as entire crop harvest from the field, severe erosion, low soil organic matter content, limited fertilizer input and inappropriate land management [1]. Application of chemical fertilizers did not get attention because there is a broad recognition that soil fertility decline is a major production constraint in the country [2]. In addition, soil acidity that induce phosphorus fixation and aluminum toxicity are the main constraints in Ethiopian high land [3]. This is particularly common in soils with pH less than 5.5, the effect being attributed mainly to nutrient deficiency and toxicity. In these soils, plants unable to obtain phosphate due to fixation except enough is applied [4]. Soil organic carbon decline is another constraint that diminish crop production in the country. However, the use of dung as fuel instead of fertilizer is estimated to reduce Ethiopia's agricultural gross domestic product by $7 \%$, which calls for introducing alternative energy sources into the rural systems. There is also strong competition for crop residue between soil fertility, animal feed and cooking fuel, and little is remaining to the soil. Although legumes are known to add $\mathrm{N}$ and improve soil fertility, the frequency of legumes in the cropping system in Ethiopian highlands is less than $10 \%$ [5], which implies that the probability of growing legume on the same land is only once in ten years. Studies suggested that future strategies for increasing crop productivity should focus on agricultural intensification through increased use of external inputs and managing the available nutrient resources more efficiently and in a sustainable way [6].

The recent paradigm shift in soil fertility management intervention indicates that integrated soil fertility management is one of the eco-friendly, cost effective and adaptive soil fertility management techniques that enable smallholder farmers to overcome the many limitations of the various soil fertility management techniques [7]. Nutrient availability, soil water content, nutrient cycling and nutrient stock improved by addition of organic materials [8]. Integrated use of various soil fertility amendment inputs can alleviate nutrient problems and improve their availability through interactions with the mineral soil and reduce the P sorption capacity of the soil [9]. However, due to the continuous decrease in organic matter and nutrient content of the soil, the importance of integrated nutrient management for efficient utilization of nutrient and long-term maintenance of soil fertility has been required [10].

Combination of different farming systems and agronomic practice can help address the problems of soil fertility decline instead of concentrating on chemical fertilizer alone, integrating different practices which are acceptable and minimize the expenditure of poor farmers like green manure, crop rotation, intercropping, compost in combining with mineral fertilizers and improved varieties. Soil nutrient balance studies showed evidence of widespread nutrient mining leading to severe nutrient deficiencies across ecological zones. Soil nutrient stocks are not static entities and studies in different areas at different spatial scales show that nutrients are being depleted at alarming rates [11]. Nutrients are annually taken away in crops or lost in processes such as leaching and erosion which far exceed the nutrient inputs through fertilisers, deposition and biological fixation [11]. This study used resource/nutrient flows to work with farmers to better understand their current practice, their constraints, and their opportunities for reversing nutrient depletion. Knowledge of nutrient stocks and flows is a key for convincing policy makers and reversing soil degradation and improve soil fertility and crop production. Therefore, the objective of this paper was to review nutrient flows and balances in small holder farms of Ethiopia. 


\section{Nutrient Cycle and Flows}

Soil nutrient availability changes over time. The continuous recycling of nutrients into and out of the soil is known as the nutrient cycle. The cycle involves complex biological and chemical interactions, some of which are not yet fully understood. A simplified version of this cycle of plant growth, based on [12], is classified as "inputs" that added plant nutrients to the soil and "outputs" that export them from the soil largely in the form of agricultural products. Important input sources include inorganic fertilizers, such as manure, plant residues, and cover crops, nitrogen generated by leguminous plants and atmospheric nitrogen deposition. The quantity of nutrient inputs via wet deposition depends on the amount of precipitation and agro ecology of the area. The method of Stoorvogel [12] was used to estimate wet deposition as the square root of average annual rainfall using coefficients of 0.014 for $\mathrm{N}, 0.053$ for $\mathrm{P}$ and 0.11 for K. Nutrient added to a field in different ways. These additions mainly include mainly mineral fertilizers, manures and crop residue. Most of the inputs are directly added to the field, for instance, mineral fertilizers, crop residue application, while others pass through intermediate system components, such as animal manure and biological fixation. Nutrients are exported from the field through harvested crops and crop residues removals, as well as through leaching, atmospheric volatilization and erosion.

A nutrient balance for a system consists of the sum of nutrient inputs minus the sum of nutrient outputs. This system always represents a particular spatial scale, and it can range from a small soil aggregate to the entire globe. In agricultural activities, nutrients are added to the systems (via fertilization), nutrients are exported from them (via harvesting yields or collecting crop residues), and other nutrients are either added by environmental processes (e.g., atmospheric deposition, nitrogen fixation) or lost (e.g., nutrients in eroded soil particles, leaching). Hence, nutrient balance can be obtained by calculating the net difference between the amount of nutrients that are entering a system and the nutrients that are removed from the [13]. Positive nutrient balances in the soil occurring when nutrient additions to the soil are greater than the nutrients removed from the soil, indicate that farming systems are inefficient and, in the extreme, that they may be polluting the environment. On the other hand, negative balance could well indicate that soils are being mined and that farming systems are unsustainable over the long time. In the latter instance, nutrients have to be replenished to maintain agricultural output and soil fertility into the future [14].

\section{Mechanism of Nutrient Export from the Field}

Most of the inputs are directly added to the field, for instance, mineral fertilizers, crop residue application, while others pass through intermediate system components, such as animal manure and biological nitrogen fixation.

Mineral Fertilizer: Manufactured fertilizers are produced by the fertilizer industry. A wide range of products, supplying one or more essential mineral nutrients, are available to farmers. On average, world farmers apply some 180 million tons of fertilizers (on a nutrient basis) annually to supplement nutrient sources available on/ near their farm, and achieve their sustainable yield and quality goals. Fertilizers containing only one primary macronutrient are referred to as 'straight' fertilizers. Those with two or three primary macronutrients are called 'multi-nutrient' fertilizers. Multi-nutrient fertilizers can be either compounds/complexes (all nutrients in the same granule) or bulk blends (physical mixing of different granules). Each fertilizer product has its own advantages and disadvantages, which may depend on the local agro-ecological and economic conditions.

Manure: Organic fertilizers represent a wide group of materials derived from agricultural by-products, plants, and animal husbandry, such as manures and litters. They are essential especially for soil microorganisms, which decompose fertilizer's matter to grow and release fertilizer's nutrients into the soil environment. The nutrients then can be utilized by arable crops and support theirs grow and development. The process of mineralization performed by the soil microorganisms release fertilizer's nutrients into the environment, allowing arable crops to grow and develop properly. The ratio of the profit significantly depends on the kind of organic fertilizer. Fertilizers with low $\mathrm{C} / \mathrm{N}$ ratio release their nutrients rapidly and in a relatively huge proportion during the first year, fertilizers with high $\mathrm{C} / \mathrm{N}$ ratio (farmyard manure) release their nutrients slowly but for a longer time period. The process of mineralization also depends on the climate conditions, decreasing significantly with the occurrence of dry periods. The main contribution of organic fertilizers, however, lies in the addition of organic matter to the soil [15], influencing soil chemical, physical, and biological properties.

Crop residue: Crop residues include the above-ground biomass of plants remaining in the field after grains, tubers and other products have been collected. The crop residues are incorporated into the soil and /or left as mulch [16]. It is a way of directly recycling nutrients into the soil taken by the plants from the soil earlier. It is used for soil protection and soil fertility improvement [17]. Normally in Ethiopia crop residues are removed for animal feed $[18,19)$. Crop residues, such as leaves, stems and roots, when left on or in the soil, release the nutrients they contain. Crop residues are mainly rich in $\mathrm{K}$. That is why residue incorporation has, over the years been the chief source of this element. However, burning and conversion into livestock feed has gradually depleted $\mathrm{K}$ reserves in the soil. Crop residues vary greatly in nutrient content, and the amount of plant available nutrients that are released in a specific time period can only be determined from local data. 
Biological fixation: Biological $\mathrm{N}$ fixation, the conversion of atmospheric $\mathrm{N}$ to plant usable compounds. A major source of $\mathrm{N}$ to many crops and natural vegetation is derived from legumes (woody and herbaceous). The quantities fixed from the air vary with the species, the fertility conditions of the soil and overall climatic conditions. The quantities fixed range from a high of 212-290 kg Nha ${ }^{-1}$ for alfalfa (Medicago sativa), white clover (Trifolium repens) and Egyptian clover (Trifolium indica) to lows of 10-30 kg of Nha ${ }^{-1}$ for common bean (Phaseolus vulgaris) and English pea (Pisum sativum). Soils low in available P and legume seeds that are poorly inoculated and planted in very acid soils frequently fix comparatively small quantities of $\mathrm{N}$. In many of the region's soils, the crop will not fix much $\mathrm{N}$ unless the $\mathrm{pH}$ and $\mathrm{P}$ problems of the soil are corrected. The $\mathrm{BNF}$ process requires and consumes considerable amounts of energy to fix $\mathrm{N}$ from the atmosphere and is very sensitive to stress conditions in soil (i.e., acidity, water and phosphate availability etc). In cropping systems used in areas extremely short of land and striving for maximum production, the $\mathrm{N}$ derived from legumes through the biological fixation process and related energy expended to fix this $\mathrm{N}$ must be carefully weighed against other alternative sources of supply.

Atmospheric deposition: Atmospheric deposition can be significant in some areas, especially for $\mathrm{N}$ and $\mathrm{S}$. In response to regulations reducing $\mathrm{S}$ emissions to mitigate related acid rains, this input has been declining over time, $\mathrm{S}$ has become an increasingly limiting factor, and $\mathrm{S}$ fertilization is now becoming a common practice in developed countries and more and more in emerging and developing economies. Nutrient deposition - the amounts of nutrients that return to the soil by deposition. Deposition is associated mainly with the levels of nutrients used (and produced) and with the amount of rainfall. Atmospheric deposition formed in two ways. Wet deposition, which means nutrients derived through rainfall and dry deposition, e.g., dust originating from the Sahara Desert, or volcanic ash

\section{Mechanism of Nutrient Export from the field}

Nutrients are exported from the field through harvested crops and crop residues, as well as through leaching, atmospheric volatilization and erosion.

Removal of harvested crop: Nutrients are removed from the soil in harvested materials that leave the field. The quantity of nutrient removed is less than total uptake and varies significantly with crop species, yield, where the nutrient is stored in the plant and the portion of the crop that is removed. The second major loss of nutrients to the soil is caused by the failure of farmers and herdsmen to recycle crop residues and manures back to the soils. This creates a nutrient deficit in the soil. More importantly this deprives the soil of a major source of organic matter needed to protect existing nutrients from further loss or immobilization. There is ample, albeit indirect, evidence that there are strong external forces (demand for energy, fodder and building materials) competing for crop residue produced on-farm. As a result, the nutrients available to the crop are frequently diverted to non-farm uses (in the case of forage, non-crop uses) with the net effect that basic soil fertility and overall crop production declines.

Erosion: Nutrient loss due to soil erosion is perhaps the number one threat to the productivity of crop-livestock systems. Severity of erosion in all these regions is attributed to high population density, soils that are prone to erosion due to both harsh climate and intensive arable land use, uncontrolled grazing and excessive stocking rates, and soil profile characteristics that render them susceptible to under cutting and gully erosion.

Leaching and Gaseous loses: Leaching is the downward movement of water and soluble substances in soil below the root zone. It is an environmental concern when it contributes to groundwater contamination. Leaching occurs during periods of wet weather, at certain times of year (most likely early spring and late fall) and in certain places in the landscape, especially in sandy soils. Depressions in the landscape where groundwater recharge occurs are more susceptible to leaching because they collect water from surrounding areas, particularly during heavy rainfall events or during snowmelt runoff over frozen soils, which then moves downward to groundwater. Nitrogen, when converted and applied as urea, nitrate, ammonia or ammonium form to the surface of most soils, is prone to losses either through leaching or gaseous avenues (denitrification or volatilization).

In addition, $\mathrm{S}$ in the sulfate form can be lost through leaching or if burned in crop residues, can be volatilized. Up to $60 \%$ of $\mathrm{N}$ and $\mathrm{S}$ can be lost if crop residues are burned. Anywhere from $10-50 \%$ of the $\mathrm{N}$ in fertilizer can be lost if surface applied as urea. The availability of $\mathrm{N}$ declines as manures age and are composted. As manures are exposed to wetting, drying and microbial activity, the inorganic forms of manure are lost by leaching and volatilization and the more readily decomposed organic $\mathrm{N}$ compounds are converted to more stable forms. In general, composts and manures containing less than $1.5 \% \mathrm{~N}$ (dry basis) will supply little or no $\mathrm{N}$ to crops in the first few weeks. Moist manure, when exposed to the air, undergoes significant loss of $\mathrm{N}$ as volatile ammonia. Losses can reach 15\%/day and be especially severe if surface applied on warm windy days when the evaporative potential is high.

\section{Nutrient balance in farming system}

Soil nutrient depletion coupled with low fertilizer use, is the main cause of soil fertility decline in Ethiopia and 
nutrient balances in the Ethiopian farming systems are generally negative as a result $[20,21,22]$. Assessment conducted in the Central Highlands of Ethiopia indicated that nutrient balances were more negative in teff cropping systems $\left(-28 \mathrm{~kg} \mathrm{~N} \mathrm{ha}^{-1}\right)$ than in enset $\left(-6 \mathrm{~kg} \mathrm{~N} \mathrm{ha}^{-1}\right.$ [23]. The differential application of organic and mineral fertilizers on a farm over many years, aggravated by erosion, commonly creates a clear soil fertility gradient from the homestead to the outfield $[24,25,26]$. Study conducted in southern Ethiopian farming systems revealed that soil nutrient status commonly decreased from the homestead to the outfields, regardless of resource endowment categories [27].

Soil nutrient flow and balance assessment in southern Ethiopia showed that nutrient distribution varied among landscapes, households, farms and farm subunits. In these systems, a high concentration of nutrients in the homestead is created because nutrients move from the house to the home garden in the form of household refuse, mineral fertilizers, animal manures [28]. The nutrients flow from the outside fields to the homestead fields in the form of grain crop residues for feed, mulch, fuelwood and other uses. In general, the home garden fields are characterized by a positive nutrient balance while the outfields have a negative nutrient balance [29]. A shortage of organic waste and manure also limits its application to home garden crops as the outfields are commonly exposed to heavy erosion losses and theft of high-value crops [30]. Soil nutrient losses caused by erosion under cereals and other annuals at a country scale. Of the total nutrients removed from cereal cropping, about $70 \%$ of $\mathrm{N}, 80 \%$ of $\mathrm{P}$ and $63 \%$ of $\mathrm{K}$ were removed by erosion [31].

Table 1. Determinants of nutrients depletion under different cropping systems in Ethiopian smallholders

\begin{tabular}{|c|c|c|c|c|c|c|c|c|c|c|c|}
\hline \multicolumn{3}{|c|}{ Harvested products } & \multicolumn{3}{|c|}{ Residual removal } & \multicolumn{2}{|c|}{ Lecheang } & \multirow{2}{*}{$\frac{\text { Denitrification }}{\mathrm{N}}$} & \multicolumn{3}{|c|}{ Erosion } \\
\hline $\mathrm{N}$ & $\mathrm{P}$ & $\mathrm{K}$ & $\mathrm{N}$ & $\mathrm{P}$ & $\mathrm{K}$ & $\mathrm{N}$ & $\mathrm{K}$ & & $\mathrm{N}$ & $\mathrm{P}$ & $\mathrm{K}$ \\
\hline 10 & 19.4 & 6 & 4 & 5 & 11 & 9 & 17 & 3 & 74 & 80 & 66 \\
\hline 14 & 16.8 & 13 & 4 & 3 & 8 & 8 & 17 & 2 & 72 & 84 & 62 \\
\hline 1 & 1 & 2 & 1 & 4 & 5 & 8 & 20 & 2 & 88 & 96 & 73 \\
\hline 21 & 30.4 & 25 & 19 & 31 & 34 & 22 & 22 & 12 & 24 & 44 & 19 \\
\hline 16 & 24.9 & 14 & 40 & 67 & 70 & 27 & 13 & 14 & 3 & 10 & 2 \\
\hline
\end{tabular}

Source: Haileslassie et al. [31]

A countrywide analysis of nutrient balance indicated a depletion rate of $122 \mathrm{~kg} \mathrm{~N}^{-1} \mathrm{yr}^{-1}, 13 \mathrm{~kg} \mathrm{P} \mathrm{ha}^{-1} \mathrm{yr}^{-1}$ and $82 \mathrm{~kg} \mathrm{~K} \mathrm{ha}^{-1} \mathrm{yr}^{-1}$ [31]. Soil fertility depletion and associated low agricultural productivity are serious problem in ethiopia particularly in central high lands [32]. According to, soil nutrient depletion due to inadequate soil management have gradually increased and become serious problems to crop productivity in the country due to the strong association that exists between soil properties, land scape and cultural practice [33]. Soil nutrient mining investigation at national level by FAO [34] showed that the nutrient depletion rate of Ethiopian soil was $47 \mathrm{~N},-7 \mathrm{P}$ and $-32 \mathrm{~K} \mathrm{~kg} \mathrm{ha}^{-1}$. These were about twice as much as the average depletion rates for Sub Saharan Africa $-22 \mathrm{~kg} \mathrm{~N},-2.5 \mathrm{~kg} \mathrm{P}$ and $-15 \mathrm{~kg} \mathrm{~K} \mathrm{ha}^{-1} \mathrm{yr}^{-1}$ and it indicated the severe magnitude of soil nutrient depletion in Ethiopia. The declining of soil fertility and quality had led to low crop yield especially like wheat, barley and teff crop. For example, the current average national wheat yield is about $2.76 \mathrm{t}^{\mathrm{ha}^{-1}}$ [35], which is well below experimental yields of $5 \mathrm{t}$. ha ${ }^{-1}[36]$.

Study of soil nutrient depletion and its spatial variability for Ethiopia and its regional states, were assessed using nutrient balances as a tool used by both USLE and LAPSUS approaches [37]. The full nutrient balance results also demonstrated the large inter-regional variability. Variations across the regions were mainly caused by differences in soil fertility, precipitation, area under various crops, and slope steepness. The balance for the state of Oromia was strongly negative $\left(-128 \mathrm{~kg} \mathrm{~N} \mathrm{ha}^{-1} \mathrm{yr}^{-1},-13 \mathrm{~kg} \mathrm{P} \mathrm{ha}^{-1} \mathrm{yr}^{-1},-84 \mathrm{~kg} \mathrm{~K} \mathrm{ha} \mathrm{yr}^{-1}\right)$ than other regional states. Trends of full nutrient balances results (both LAPSUS and USLE approaches) were similar across the regions. Less negative values of nutrient balances in the LAPSUS approach can be explained by the lower estimate of erosion. $\mathrm{N}$ depletion in the regions with less intensive management (Afar, Somali) was in the range of $51 \mathrm{~kg} \mathrm{ha}^{-1} \mathrm{yr}^{-1}$ to $24 \mathrm{~kg} \mathrm{ha}^{-1} \mathrm{yr}^{-1}$. Despite higher fertilizer application and intensive farming, Tigray region also belonged to this group. This was largely due to, lower rainfall, lower biomass production and lower soil fertility. Aggregation of some balance's parameters (biomass productivity) to the regional scale masked the highly degraded areas in the Northern Amhara region which otherwise would have similar degree of balance like the less intensive cultivated regions. Trends in losses of $\mathrm{K}$ were comparable to N. Literature indicated that Ethiopian soils have a good stock of $\mathrm{K}$ and crops are not responsive to potassium fertilizer. However, this does not exclude the possibility that there are areas within each region where K may be limiting [37].

Noticeable variations were observed among the regional states (Table 2). States with a higher rate of fertilizer or dung input (SNNPR, Oromiya, Addis Ababa, and Harari) have a positive partial balance even though harvests were also higher. An exceptional case was the Amhara region, where a high amount of dung is used for household energy sources and thus, the partial balance was negative [38]. Addis Ababa also showed a negative balance for K, caused by a low Input, (major sources of K). We observed apparently strong positive balances of $\mathrm{N}$ and $\mathrm{P}$ in Addis Ababa. Higher inorganic and organic sources of nutrient inputs and relatively strong positive partial nutrient balances, in intensively cultivated regions, reflect the level of agricultural development, market 
proximity and higher prices for the agricultural products [39]. In Somali, Afar and Gambela (Table 2), the level of inputs was clearly lower than the outputs output, resulting in a negative partial balance for all nutrients. The strongest negative balance was found in Gambela, an area with a subhumid climate and relatively high yields (compared to the semi-arid regions). This relation between management intensity and nutrient depletion was also reported earlier [40]. At the national scale, the partial balances were positive for all nutrients considered.

Table 2. Partial nutrient balances by Ethiopian regional states in $\mathrm{kg} \mathrm{ha}^{-1} \mathrm{yr}^{-1}$

\begin{tabular}{|c|c|c|c|c|c|c|c|c|c|}
\hline \multirow{2}{*}{ Region } & \multicolumn{3}{|l|}{ Input } & \multicolumn{3}{|c|}{ Out put } & \multicolumn{3}{|c|}{ Balances } \\
\hline & $\mathrm{N}$ & $\mathrm{P}$ & $\mathrm{K}$ & $\mathrm{N}$ & $\mathrm{P}$ & $\mathrm{K}$ & $\mathrm{N}$ & $\mathrm{P}$ & $\mathrm{K}$ \\
\hline Tigray & 29.4 & 10.7 & 25.2 & 18.5 & 4.6 & 14.8 & 10 & 6 & 10 \\
\hline Affar & 0 & 0 & 0 & 10.1 & 2.8 & 9.3 & 10 & 3 & 9 \\
\hline Amhara & 21.8 & 11.1 & 15.6 & 22.7 & 5.3 & 18.2 & 1 & 6 & 2 \\
\hline Oromia & 42.8 & 20 & 38.8 & 28.5 & 6.9 & 28 & 14 & 13 & 11 \\
\hline Somali & 0 & 0 & 0 & 7.8 & 2.2 & 7.7 & 8 & 2 & 8 \\
\hline Benishangul & 30.4 & 8.3 & 34 & 17.6 & 4.4 & 15.2 & 13 & 4 & 19 \\
\hline SNNPR & 81.3 & 30.5 & 85 & 45.9 & 8.5 & 65.4 & 35 & 22 & 19 \\
\hline Gambela & 0 & 0 & 0 & 19.6 & 5.8 & 23.9 & 20 & 6 & 24 \\
\hline Harari & 60.8 & 20.4 & 59.5 & 25.7 & 6.1 & 22.3 & 35 & 14 & 37 \\
\hline Addis ababa & 62.6 & 65.7 & 0 & 23.5 & 4.2 & 12.9 & 39 & 61 & 13 \\
\hline Diredawa & 30 & 22.3 & 12.3 & 17.2 & 3.5 & 12.5 & 13 & 19 & 0 \\
\hline National & 37.5 & 34.4 & 34.3 & 34.3 & 6.3 & 27.3 & 10 & 11 & 7 \\
\hline
\end{tabular}

Source: Henao et al. [40]

Nutrient flow and balances at field and farm scale was studied at Galesa (Enset-based farming system) and Gare (Teff-based farming system) watersheds are situated in the Central Highlands of Ethiopia. Full nutrient balances indicated a considerable $\mathrm{P}$ accumulation in enset-based farming systems. In contrast, in teff-based systems, $\mathrm{P}$ was under slight depletion. The latter also had a negative $\mathrm{N}$ and $\mathrm{K}$ balance that is a five-fold higher depletion rate of $\mathrm{N}$ and a two-fold higher depletion of $\mathrm{K}$ than the enset-based farming system. Crop-specific partial nutrient balances in enset- and teff-based farming systems in the Central Highlands of Ethiopia were $-6 \mathrm{~N}$, $+11 \mathrm{P},-14 \mathrm{~K}$ and $-28 \mathrm{~N},-1 \mathrm{P},-34 \mathrm{~K} \mathrm{~kg} \mathrm{ha}^{-1} \mathrm{yr}^{-1}$ ) respectively [41]. However, the differences between the twofarming system are due to elevation which may influencing the nutrient cycle and parent materials thus contributed to the pedogenic differences between them. Therefore, differences in soil properties encountered within a watershed were assumed to be related to topography factors and to land use and management practices in two farming system. In both farming systems, soils close to homesteads had higher organic matter content than other soils. These results illustrate the importance of niche management by which farmers deliberately enrich certain fields to increase production [42]. However, there are risks related to this land use strategy, as nutrient enrichment in one place often brings about nutrient impoverishment elsewhere.

Similar study conducted at small spatial scales at two agro-ecological zones (highland and lowland), in southern Ethiopia at Kindo kasha representing four socio-economic groups of farmers in terms of their resources (rich, medium, poor and very poor) were showed varied results. For highland, farms with household groups of rich, medium, poor, and very poor, the values were $-47,-51,-19$ and $-6 \mathrm{~N} \mathrm{~kg} \mathrm{ha}^{-1} \mathrm{yr}^{-1}$ respectively. In contrast, in lowlands with household groups of rich, medium, poor and very poor the values were $-49,-41,-55$ and $-20 \mathrm{~N} \mathrm{~kg}$ $\mathrm{ha}^{-1} \mathrm{yr}^{-1}$ respectively.However, the $\mathrm{P}$ balance was positive for most farms [43]. Poorer farmers had lower $\mathrm{N}$ depletion rates, which may seem contradictory. However, they can compensate for lower mineral fertilizer inputs by intensive soil enriching and nutrient conserving practices, including rational use of available manure; systematic management and recycling of crop residues; collection of leaf litter; and improved soil conservation. The enset, taro and darkoa (homestead) fields received many inputs and therefore had a positive or neutral balance, but the shoka (out fields) had very negative balances owing to low input [43].

Likewise, soil nutrient flow and balance assessment at small holders farming system of Jimma Zone indicated that $\mathrm{N}, \mathrm{P}$ and $\mathrm{K}$ added to the crop farm through inorganic and organic sources were much less than nutrient removed out of the system. Poor integrated soil fertility management practices, in effective use of locally available nutrient and high cost of commercial fertilizer become the cause for unsustainable agricultural production in the area [44]. The mean values for nutrient balance at farm scale were negative among wealth groups in both locations (at high and low altitude) were $-55.6 \mathrm{~N},-9.7 \mathrm{P},-49.8 \mathrm{~K}$ and $-35.7 \mathrm{~N}, 9.1 \mathrm{P}$ and $-29.7 \mathrm{~K}$ $\left(\mathrm{kg} \mathrm{ha}^{-1} \mathrm{yr}^{-1}\right)$ respectively. This implies that, the subsistence farming systems of smallholder farmers in the area is depleting soil nutrient stock. Due to high $\mathrm{P}$ fixation within the study area, $\mathrm{p}$ depletion was lower than $\mathrm{N}$ and $\mathrm{K}$ in both locations for all wealth groups.

Study conducted by Balesh [45] in central High lands of Ethiopia at micro level indicated that the average nitrogen balance was $-9 \mathrm{~kg} \mathrm{~N}$ and the depletion was highest in poor household farms. Nutrient depletion varied between the crops and grasslands had got severe depletion. Crop removal was the primary contributor to nutrient depletion followed by erosion. Enset and maize had a positive nutrient balance. The result showed that rich and 
medium wealth group farmers could afford to apply mineral fertilizers and increase nutrient inputs from organic sources as they have more access to manure and other organic materials for compost production. The poor farmers do not have such choices in the absence of a credit scheme and livestock as manure sources. Macronutrient depletions in Ethiopia are mostly caused by continuous cropping without replenishing, leaching loss, crop residue removal, low level of fertilizer use, deforestation, and inadequate runoff management [46]. Different studies had been made at a plot-based level whereby different cropping units are distinguished according to crop type, landscape position or intensity of management (often comparing dryland outfields with homefields and gardens). In southern Ethiopia, for example, comparison of enset (false banana) plots close to homesteads with intensively managed maize gardens and outfields reveals important differences in patterns of fertility management, types of nutrient cycling and levels of nitrogen and phosphorous balance at plot level [47].

Investigation made Hailu [48] in Tigray area, partial input-output nutrient balance, showed $\mathrm{N}$ in the faba

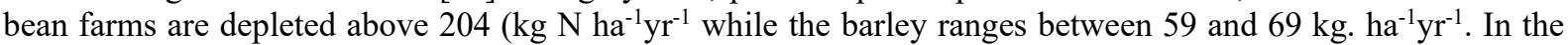
barley, the highest (negative) nutrient balance of $\mathrm{N}$ was from the control plots $\left(-69 \mathrm{~kg} \mathrm{~N} \mathrm{ha}^{-1} \cdot \mathrm{yr}^{-1}\right)$. It was due to lack of nutrient input for the compensation of the depleted nutrients. In the faba bean, the highest nutrient balance was from both compost applications especially the $3.2 \mathrm{t}^{.} \mathrm{ha}^{-1} \mathrm{yr}^{-1}$ compost application plots i.e., $-228 \mathrm{~kg}$ $\mathrm{N}$ ha ${ }^{-1} \cdot \mathrm{yr}^{-1}$. The lowest balance for $\mathrm{N}$ in barley crop is for the plots with mineral fertilizer. It is because the amount of $\mathrm{N}$ added as mineral fertilizer holds higher compensation. In faba bean, the lowest is from both the control and mineral fertilizer applied plots. The partial input-output nutrient balance for $\mathrm{P}$ in the barley showed all treatments and the control are negative but the plots with mineral fertilizer application are positive $(+7.8 \mathrm{~kg}$. $\left.\mathrm{ha}^{-1} \mathrm{yr}^{-1}\right)$. In the faba bean crop mineral fertilizer applied fields are still the lowest depletion $\left(-5.6 \mathrm{~kg} \mathrm{ha}^{-1} \mathrm{yr}^{-1}\right)$ nearer to an equilibrium. This is directly the reflection of the application of mineral fertilizer. Highest depletions in barley and faba bean are in the 3.2 and $6.4 \mathrm{t} \mathrm{ha}^{-1} \mathrm{yr}^{-1}$ compost applications respectively. This is the reflection of the smaller amount of phosphorous applied by the composts. The partial nutrient balance showed depletion of $\mathrm{K}$ is high in all crops and treatments. The lowest depletion was potassium i.e., 188 and $236 \mathrm{~kg}^{\text {. ha-1 }} \mathrm{yr}^{-1}$ in barley and faba bean respectively are in the control plot. While the highest depletion observed in the mineral fertilizer plots i.e., -247 and $-269 \mathrm{~kg}$. ha ${ }^{-1} \cdot \mathrm{yr}^{-1}$ for barley and faba bean respectively. This is directly the reflection of the type of input and dependent on the amount of yield. Because there was no much difference in the NPK content of the grains and straw [48].

Huge amount of nutrients was removal by crop cultivation especially by faba bean. The control plot has the lowest removal in both crops, which corresponds with its lower production which was highly related to amount of input induced especially no $\mathrm{K}$ application through mineral fertilizer. On the other hand, whenever input is applied to the soil, production and nutrient removal increases. This removal shows that the soil nutrients are highly exploited by the crop production system. Much of the removal in all crops is from straw than grain. For example, the NPK removal from the barley straw accounts 50-58, 89-91 and 93-94 percent while from faba bean it is 55-59, 70-73 and 83-84 respectively to their total removal [48]

Table 3. Partial input-output balance of NPK in barley and faba bean $\left(\mathrm{kg}\right.$. $\left.\mathrm{ha}^{-1} \mathrm{yr}^{-1}\right)$

\begin{tabular}{|c|cccccc|}
\hline \multirow{2}{*}{ Treatments } & \multicolumn{4}{|c|}{ Barley } & \multicolumn{2}{c|}{ Faba bean } \\
\cline { 2 - 7 } & Input & Out put & $\begin{array}{c}\text { partial } \\
\text { balance }\end{array}$ & Input & Out put & $\begin{array}{c}\text { partial } \\
\text { balance }\end{array}$ \\
\hline Check & 0 & 69.2 & -69.2 & 125 & 328.7 & -203.7 \\
(N) Mineral fertilizer & 39 & 98.1 & -59.1 & 164 & 368.5 & -204.5 \\
3.2 t. ha compost & 18.2 & 79.5 & -61.5 & 143.2 & 371 & 227.8 \\
6.4 t. ha ha $^{-1}$ compost & 36.5 & 98.9 & -62.4 & 161.5 & 386.1 & -224.6 \\
\hline \hline Check & 0 & 7.7 & -7.7 & 0 & 20.6 & -20.6 \\
Mineral fertilizer & 18 & 10.2 & 7.8 & 18 & 23.6 & -5.6 \\
3.2 t. ha compost & 1.1 & 9.7 & -8.6 & 1.1 & 22.1 & -21 \\
6.4 t. ha ${ }^{-1}$ compost & 2.3 & 10.2 & -7.9 & 2.3 & 25.6 & -23.3 \\
\hline \hline Check & 0 & 187.5 & -187.5 & 0 & 235.9 & -235.9 \\
(K) Mineral fertilizer & 0 & 247 & -247 & 0 & 268.9 & -268.9 \\
3.2 t. ha ${ }^{-1}$ compost & 16 & 227 & -211 & 16 & 280.2 & -264.2 \\
6.4 t. ha ${ }^{-1}$ compost & 32 & 246.4 & -214.4 & 32 & 286.3 & -254.3 \\
\hline
\end{tabular}

Source: Hailu [48]

\section{CONCLUSIONS AND RECOMMENDATIONS}

From this review, it can be concluded that there is higher nutrient mining rate, particularly for $\mathrm{N}, \mathrm{P}$ and $\mathrm{K}$ in different land use types and under different cropping systems due to high removals of nutrients in erosion, harvested output and residue as a result of poor nutrient management. Difference in application of mineral fertilizer and organic inputs also led difference in nutrient depletion rates among socio-economic groups. These 
differences could associate with the differences in crop production as the result of chemical and physical soil fertility of the cultivated fields-based nutrient-management techniques, such as soil conservation. Under the prevailing natural and socio-economic conditions, farmers' current practices are inadequate to cope with the decline in soil fertility at farm level condition. Therefore, it needs targeted agronomic interventions, use of integrated nutrient management approach, proper management of crop residues and awareness creation to mitigate nutrient losses and to improve sustainability of crop production.

\section{Acknowledgement}

None.

\section{Conflict of Interest}

No conflict of interest.

\section{REFERENCES}

1. Getachew, A., P.N. Nelson., M.I. Bird. 2016.Crop yield, plant nutrient uptake and soil physicochemical properties under organic soil amendments and nitrogen fertilization on Nitisols. Soil and Tillage Research, 160:1-13.

2. Amede, T. 2006. Managing nutrient on the move within the rural-urban context. In: Gete Zeleke, P. Truttmann and A. Denekew.

3. Getachew, A., G. Amare and S. Woldeyesus. 2006. Yield performance and land-use efficiency of barley and faba bean mixed cropping in Ethiopian highlands. European Journal of Agronomy 25:202-207. Available online at www.sciencedirect.com

4. Marschner, H; Rimmington, G. 1988. Mineral nutrition of higher plants. Plant Cell Environ 11:147-148.

5. Getachew, A., Berhane, L. and Nelson, P. 2014. Cropping sequence and nitrogen fertilizer effects on the productivity and quality of malting barley and soil fertility in the Ethiopian Highlands. Journal of Agronomy and Soil Science, 60: 1261-1275.

6. Gruhn P; Goletti F; Yudelman M. 2000. Integrated nutrient management, soil fertility, and sustainable agriculture: current issues and future challenges. International Food Policy Research Institute (IFPRI).

7. Vanlauwe, B., Descheemaeker, K., Giller, K. E., Huising, J., Merckx, R., Nziguheba, G., and Zingore, S. 2015.Integrated soil fertility management in sub-Saharan Africa: unravelling local adaptation. Soil journal ,1: 491-508.

8. Amede T; Amézquita Collazos E; Ashby JA; Ayarza MA; Barrios E; Bationo A; Beebe SE; Bellotti AC; Blair MW; Delve RJ. 2002.Biological nitrogen fixation: A key input to integrated soil fertility management in the tropics. Workshop on Biological Nitrogen Fixation for Increased Crop Productivity, Enhanced Human Health and Sustained Soil Fertility (2002, Montpellier, France). Papers presented.

9. Sanchez P; Jama B. 2002. Soil fertility replenishment takes off in east and southern Africa. In: B. Vanlauwe, J. Diels, N. Sanginga, R. Merckx (eds), Integrated Plant Nutrient Management in sub-Saharan Africa: From Concept to Practice, CABI, Wallingford, UK, pp 23-46.

10. Haileslassie, A., Priess, J., Veldkamp, E., Teketay, D., Lesschen, J.P. 2005. Assessment of soil nutrient depletion and its spatial variability on smallholders' mixed farming systems in Ethiopia using partial versus full nutrient balances. Agriculture, ecosystems and environment, 108:1-16.

11. Smaling, E.M.A, S.M. Nandwa and B.H. Janssen. 1997. Soil fertility is at stake! In: Buresh, R.J., P. A. Sanches and F. Calhoun (eds.). Replenishing soil fertility in Africa. SSSA, Special Publication No. 51, Soil Science Society of America, Madison, USA. pp. 47-61.

12. Stoorvogel, J., Smaling, E., 1990. Assessment of Soil Nutrient Depletion Sub-Saharan Africa: 1983-2000. The Winand Staring Centre, Wageningen.

13. Smaling, E.M. A, Stoorvogel, J. J, Windmeijer, P.N. 1993.Calculating soil nutrient balances in Africa at different scales-II. District scale. Fert Res 35: 237-250.

14. Gruhn P; Goletti F; Yudelman M. 2000. Integrated nutrient management, soil fertility, and sustainable agriculture: current issues and future challenges. International Food Policy Research Institute (IFPRI).

15. Palm CA, Gachengo CN, Delve RJ.2001. Organic Inputs for soil fertility management in tropical agro ecosystems: Application of an organic resource database. Agric Ecosyst Environ 83: 27-42.

16. Smith, J.L. and Elliott, L.F. (1990): Tillage and residue management effects on soil organic matter dynamics in semiarid regions. Adv Soil Sci, 13: 69-87

17. Elias, E. 2002. Farmers' perceptions of soil fertility change and management. ISD and SOS Sahel International (UK). EDM Printing Press. Addis Ababa, Ethiopia

18. Araya, H. and Edwards, S. 2006. The Tigray experience: A success story in sustainable agriculture. Environment and Development Series 4, Third World Network, Penang.

19. Elias, E. 2002. Farmers' perceptions of soil fertility change and management. ISD and SOS Sahel 
International (UK). EDM Printing Press. Addis Ababa, Ethiopia

20. Haileslassie, A., Priess, J., Veldkamp, E.2005. Assessment of soil nutrient depletion and its spatial variability on smallholders' mixed farming systems in Ethiopia using partial versus full nutrient balances. Agric Ecosyst Environ 108: 1-16.

21. Abegaz, A., van Keulen, H., Haile, M., Oosting, S, J. 2007. Nutrient dynamics on smallholder farms in Teghane, Northern Highlands of Ethiopia. Advances in integrated soil fertility management in sub-Saharan Africa: Challenges and opportunities. Springer, pp 365-378.

22. Kraaijvanger, R; Veldkamp T. 2015. Grain productivity, fertilizer response and nutrient balance of farming systems in Tigray, Ethiopia: A multiperspective view in relation to soil fertility degradation. Land Degradation \& Development, 26:701-710.

23. Haileslassie, A., Priess, J. A; Veldkamp, E. Nutr Cycl Agroecosyst. 2006. 75: 135.

24. Tittonell, P., Vanlauwe, B., Leffelaar, P.A., Shepherd, K.D., Giller, K.E. 2005. Exploring diversity in soil fertility management of smallholder farms in western Kenya: II. Within-farm variability in resource allocation, nutrient flows and soil fertility status. Agriculture, Ecosystems and Environment, 110:166-184

25. Tscharntke, T., Clough, Y., Wanger, T.C., Jackson., Motzke, I., Perfecto, I., Vandermeer. J., Whitbread, A. 2012. Global food security, biodiversity conservation and the future of agricultural intensification. Biological Conservation, 151:53-59.

26. Amede, T, Taboge, E. 2007. Optimizing Soil Fertility Gradients in the Enset (Ensete ventricosum) Chapter26 Systems of the Ethiopian Highlands: Trade-offs and Local Innovations. Advances in Integrated Soil Fertility management in Sub-Saharan Africa: Challenges and Opportunities. Springer. pp 289-297.

27. Eyasu E., Morse, S., Belshaw, D.R.G., 1998. Nitrogen and Phosphorus Balances of Kindo Koisha Farms in Southern Ethiopia. Agric. Ecosyst. Environ, 71: 95-116.

28. Eyasu, E. 1998. Is Soil Fertility Declining? Perspectives on Environmental Change in Southern Ethiopia. IIED. Drylands programme. Fageria N; Baligar V. 1997. Integrated plant nutrient management for sustainable crop production-an overview. International Journal of Tropical Agriculture ,15:1-18.

29. Vanlauwe, B., Tittonell, P, Mukalama, J. 2006. Within-farm soil fertility gradients affect response of maize to fertiliser application in western Kenya. Nutr Cycl Agroecosyst 76:171-182. Fostering new development pathways: Harnessing rural-urban linkages to reduce poverty and improve environment in the highlands of Ethiopia. Global Mountain Programme of CIP. pp 122-132.

30. Amede, T, Taboge, E. 2007. Optimizing Soil Fertility Gradients in the Enset (Ensete ventricosum) Chapter26 Systems of the Ethiopian Highlands: Trade-offs and Local Innovations. Advances in Integrated Soil Fertility management in Sub-Saharan Africa: Challenges and Opportunities. Springer. pp 289-297.

31. Haileslassie, A., Priess, J., Veldkamp, E.2005. Assessment of soil nutrient depletion and its spatial variability on smallholders' mixed farming systems in Ethiopia using partial versus full nutrient balances. Agric Ecosyst Environ 108: 1-16.

32. Wassie, H. and Shiferaw, B. 2011. Response of Irish Potato (Solanum tuberosum) to the Application of Potassium at Acidic Soils of Chencha, Southern Ethiopia. International Journal of Agriculture and Biology, 13: 595-598.

33. Taye, B., and Yifru, A. 2010. Assessment of Soil Fertility Status with Depth in Wear Growing Highlands of Southeast Ethiopia. World Journal of Agricultural Science, 525-531.

34. FAO (Food and Agricultural Organization of the United State). 2003. Scaling soil nutrient balances. Italy, Rome.

35. CSA (Central Statistics Agency).2019. Agricultural sample survey of 2019 Report on area and production of major crops for private peasant holdings, meher season. Addis Ababa, Ethiopia Statistical Bulletin 589.

36. Mann, M; Warner, J. 2015. Ethiopian Wheat Yield and Yield Gap Estimation: A Small Area Integrated Data Approach. International Food Policy Research Institute (IFPRI), Addis Ababa, Ethiopia

37. Haileslassie, A., Priess, J., Veldkamp, E.2005. Assessment of soil nutrient depletion and its spatial variability on smallholders' mixed farming systems in Ethiopia using partial versus full nutrient balances. Agric Ecosyst Environ 108: 1-16.

38. Ministry of Agriculture, 2002. Woody Biomass Inventory and Strategic Planning Project Report. Ministry of Agriculture, Addis Ababa, Ethiopia.

39. Central Statistics Authority, 2000. Agricultural Sample Survey 1999/2000, vol. 1. Statistical Bulletin 227 , CSA, Addis Ababa, Ethiopia.

40. Henao, J., Baanante, C., 1999.NutrientDepletion in Agricultural Soils of Africa. International Food Policy Research Institute, USA.

41. Haileslassie, A., Priess, J., Veldkamp, E.2005. Assessment of soil nutrient depletion and its spatial variability on smallholders' mixed farming systems in Ethiopia using partial versus full nutrient balances. Agric Ecosyst Environ 108: 1-16.

42. Chuma, E, Mombeshora, B.G, Murwira, H.K, Chikuvire, J. 2000. The dynamics of soil fertility management 
in communal areas of Zimbabwe. In: Hilhorst T, Muchena F.M (Eds) Nutrients on the move-soil fertility dynamics in African farming systems. International Institute for Environment and Development, London. 45-64.

43. Elias, E. Morse, S., Belshaw, D.G.R., 1998. Nitrogen and phosphorus balance of Kindo-Koisha farms in Southern Ethiopia. Agric. Ecosyst. Environ. 71, 93-113.Journal of Tropical Agriculture, 15:1-18.

44. Abebayehu, A., Eyasu, E., and Jan, D. 2011. A comparative analysis soil nutrient balance at a farm level: a case study at Jimma zone, Ethiopia. ISSN: 1816-4978, 1-8

45. Balesh, T. 2005. Integrated plant nutrient management in crop production in the central Ethiopian highlands. PhD Dissertation, Norwegian university of life sciences.

46. Chillot Yirga, Tesfaye Agajie, Agegnew Getachew, Abebe Getnet and Kenen Gemechu. 2002. Croplivestock farming systems of the highlands of Welmera Wereda: the case of Welmera Goro benchmark site. Towards farmers ${ }^{e e}$ participatory research: In: Proceedings of Client Oriented Research Evaluation Workshop, Holetta Research Center, Holetta, Ethiopia. 147-174.

47. Eyasu, E. 1998. Is Soil Fertility Declining? Perspectives on Environmental Change in Southern Ethiopia. IIED. Drylands programme. Fageria N; Baligar V. 1997. Integrated plant nutrient management for sustainable crop production-an overview. International Journal of Tropical Agriculture ,15:1-18.

48. Hailu, R.2010.Effect of compost on soil fertility enhancement and yield increment under smallholder farming - a case of tahtai maichew district - Tigray region, Ethiopia. PhD dissertation. University of Hohenheim, Faculty of Agricultural Sciences. 